\title{
CCN activity and droplet growth kinetics of fresh and aged monoterpene secondary organic aerosol
}

\author{
G. J. Engelhart ${ }^{1}$, A. Asa-Awuku ${ }^{2}$, A. Nenes ${ }^{2,3}$, and S. N. Pandis ${ }^{1,4}$ \\ ${ }^{1}$ Department of Chemical Engineering, Carnegie Mellon University, Pittsburgh, Pennsylvania, USA \\ ${ }^{2}$ School of Chemical and Biomolecular Engineering, Georgia Institute of Technology, Atlanta, Georgia, USA \\ ${ }^{3}$ School of Earth and Atmospheric Sciences, Georgia Institute of Technology, Atlanta, Georgia, USA \\ ${ }^{4}$ Department of Chemical Engineering, University of Patras, Patra, Greece
}

Received: 13 November 2007 - Published in Atmos. Chem. Phys. Discuss.: 4 January 2008

Revised: 16 June 2008 - Accepted: 24 June 2008 - Published: 24 July 2008

\begin{abstract}
The ability of secondary organic aerosol (SOA) produced from the ozonolysis of $\alpha$-pinene and monoterpene mixtures ( $\alpha$-pinene, $\beta$-pinene, limonene and 3-carene) to become cloud droplets was investigated. A static $\mathrm{CCN}$ counter and a Scanning Mobility CCN Analyser (a Scanning Mobility Particle Sizer coupled with a Continuous Flow counter) were used for the CCN measurements. Consistent with previous studies monoterpene $\mathrm{SOA}$ is quite active and would likely be a good source of cloud condensation nuclei (CCN) in the atmosphere. A decrease in $\mathrm{CCN}$ activation diameter for $\alpha$-pinene SOA of approximately $3 \mathrm{~nm} \mathrm{hr}^{-1}$ was observed as the aerosol continued to react with oxidants. Hydroxyl radicals further oxidize the SOA particles thereby enhancing the particle CCN activity with time. The initial concentrations of ozone and monoterpene precursor (for concentrations lower than $40 \mathrm{ppb}$ ) do not appear to affect the activity of the resulting SOA. Köhler Theory Analysis (KTA) is used to infer the molar mass of the SOA sampled online and offline from atomized filter samples. The estimated average molar mass of online SOA was determined to be $180 \pm 55 \mathrm{~g} \mathrm{~mol}^{-1}$ (consistent with existing SOA speciation studies) assuming complete solubility. KTA suggests that the aged aerosol (both from $\alpha$-pinene and the mixed monoterpene oxidation) is primarily water-soluble (around $65 \%$ ). CCN activity measurements of the SOA mixed with $\left(\mathrm{NH}_{4}\right)_{2} \mathrm{SO}_{4}$ suggest that the organic can depress surface tension by as much as $10 \mathrm{~N} \mathrm{~m}^{-1}$ (with respect to pure water). The droplet growth kinetics of SOA samples are similar to $\left(\mathrm{NH}_{4}\right)_{2} \mathrm{SO}_{4}$, except at low supersaturation, where SOA tends to grow more slowly. The $\mathrm{CCN}$ activation diameter
\end{abstract}

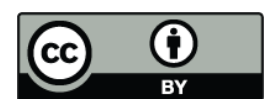

Correspondence to: S. N. Pandis (spyros@andrew.cmu.edu) of $\alpha$-pinene and mixed monoterpene SOA can be modelled to within $10-15 \%$ of experiments by a simple implementation of Köhler theory, assuming complete dissolution of the particles, no dissociation into ions, a molecular weight of $180 \mathrm{~g} \mathrm{~mol}^{-1}$, a density of $1.5 \mathrm{~g} \mathrm{~cm}^{-3}$, and the surface tension of water.

\section{Introduction}

Cloud-particle interactions are one of the major challenges in understanding indirect climate forcing (Houghton et al., 2001; IPCC, 2001). Particles in the atmosphere are composed of complex mixtures of inorganic and organic species. The subset of these atmospheric particles that activate and grow into cloud droplets at a given supersaturation are called Cloud Condensation Nuclei (CCN). Understanding CCN activation is an important step towards understanding cloud formation and properties. While we understand inorganic particles well (Köhler, 1936; Pruppacher and Klett, 1997; Svenningsson et al., 2006), many questions still remain about the influence of organic particulate material on CCN activity.

The most important organic aerosol component on a global scale is considered to be monoterpene SOA (Chung and Seinfeld, 2002). Monoterpenes represent a significant fraction of the natural volatile organic compound (VOC) emissions (Guenther et al., 1995) and can be oxidized in the atmosphere to form organic particulate matter (Seinfeld and Pankow, 2003). Early laboratory studies found that organics identified in secondary organic particles have the ability to activate as cloud droplets (Cruz and Pandis, 1997; Corrigan and Novakov, 1999). Further work highlighted the importance of small amounts of inorganic salts on organic behavior

Published by Copernicus Publications on behalf of the European Geosciences Union. 
(Bilde and Svenningsson, 2004) and revealed that hydrophobic organic coatings on inorganic cores do not appear to prevent particle activation in model aerosol systems (Cruz and Pandis, 1998). While organic coatings do not appear to prevent particle activation if sufficient time is available, they may alter growth kinetics in droplets (Feingold and Chuang, 2002; Gill et al., 1983) and this change in growth kinetics may be important in ambient aerosols (Ruehl et al., 2007). The influence of surface active species on $\mathrm{CCN}$ activation has been studied more recently. For example, Asa-Awuku et al. (2007b) have shown that the presence of salts in biomass burning aerosols depresses surface tension and, therefore, increases CCN activity. Surface tension effects have also been reported for tropospheric fine aerosol (Kiss et al., 2005).

Investigations of single component (Raymond and Pandis, 2002) and controlled mixture systems (Raymond and Pandis, 2003) created the foundation for exploration of more complex systems (Hegg et al., 2001; Broekhuizen et al., 2004; Asa-Awuku et al., 2007a) including laboratory generated SOA. Much of the previous work studying the activity of identified SOA components probed the applicability of classical Köhler theory and its extensions (Raymond and Pandis, 2002; Hori et al., 2003; Shulman et al., 1996). Classical Köhler theory assumes that the particle is fully dissolved during the activation process. Slightly soluble compounds require modifications to this theory (Shulman et al., 1996). Wettability and solubility were shown to influence particle activation (Raymond and Pandis, 2002; Padró et al., 2007) and organics were found to slow droplet growth from changes in the Köhler curve changing with droplet diameter (Shantz et al., 2003; Kumar et al, 2003).

Recent work investigating the properties of monoterpene SOA has found that particles generated from $\alpha$-pinene oxidation are good CCN (Huff Hartz et al., 2005; Prenni et al., 2007; King et al., 2007). Huff Hartz et al. (2005) used a static CCN counter to measure the activity of SOA produced from the ozonolysis of 4 monoterpenes ( $\alpha$-pinene, $\beta$-pinene, limonene and 3 -carene) and 3 sesquiterpenes ( $\beta$-caryophyllene, $\alpha$-humulene, and $\alpha$-cedrene). King et al. (2007) studied the activation of $\alpha$-pinene SOA formed on ammonium sulfate seeds with a DMT CCN counter and reported activation at atmospherically relevant sizes and compositions. Prenni et al. (2007) studied 3 monoterpene precursors ( $\alpha$-pinene, $\beta$-pinene, and 3 -carene) and found that the DMT CCN activation was attained at supersaturations relevant to the atmosphere and that CCN activity was comparable for all precursors. This work also placed the relevant monoterpene work in a novel framework based on a single fitted hygroscopicity parameter, $\kappa$ (Petters et al., 2007).

VanReken at al. (2005) used a prototype Cylindrical Continuous-Flow Streamwise Thermal Gradient (CFSTG) counter (Roberts and Nenes, 2005) to study the CCN activity of SOA produced from 4 monoterpene precursors $(\alpha$-pinene, $\beta$-pinene, limonene and $\Delta^{3}$-carene. Their results, in contrast to the above studies, showed a decrease in activity with time, attributed to oligomerization of SOA due to aging, leading to a far lower CCN activity than reported in other recent studies. While oligomerization would make the SOA particles less hygroscopic, second-generation SOA products can be further oxidized by hydroxyl radicals (Zhang et al., 2006), which could reduce the activation diameter of SOA with time. The impact of this oxidation on $\alpha$-pinene SOA CCN activity has not been explicitly studied and this discrepancy of the VanReken et al. (2005) study with the rest has not been resolved.

In this work, we investigate the CCN activity of fresh and aged $\alpha$-pinene and mixed monoterpene SOA in order to add to the growing body of evidence of understanding of monoterpene CCN activity. The applicability of singleprecursor SOA results to complicated monoterpene systems is investigated as well as the potential change in $\mathrm{CCN}$ activity with time. Two different $\mathrm{CCN}$ counters are used for the measurements: a static diffusion chamber and a cylindrical CFSTG counter operated in series with a scanning mobility particle sizer. In addition to online measurements of aerosol properties, filter SOA samples were collected and subsequently analyzed offline in the laboratory, by measuring the $\mathrm{CCN}$ activity of aerosol generated from the filter samples. Combination of these activation experimental data with Köhler theory provides estimates of the molar volume and surfactant characteristics of the SOA water-soluble organic carbon (WSOC) fraction (Asa-Awuku et al., 2007a). These offline samples are also mixed with ammonium sulfate to infer the presence and surfactant characteristics of the WSOC in the aged SOA. The droplet growth kinetics of the online and offline samples are measured and compared against that of ammonium sulfate. Finally, a simple parameterization of $\mathrm{CCN}$ properties of this important class of SOA is introduced.

\section{Experimental methods}

\subsection{Smog chamber reactor}

Experiments in this study were conducted in the Carnegie Mellon University smog chamber, a $12 \mathrm{~m}^{3}$ Teflon reactor (Welch Fluorocarbon) suspended inside a temperaturecontrolled room with a suite of sampling instrumentation. Details of the smog chamber and its operation are reported elsewhere (Presto et al., 2005a, b; Stanier et al., 2007). Prior to each experiment the reactor was cleaned with dry, particlefree air (created from compressed air passed through a HEPA filter to remove particles), an activated carbon filter to remove organic vapors, and silica gel to remove moisture. All experiments were conducted at low relative humidity (3$8 \%$ ) at approximately $22^{\circ} \mathrm{C}$. The particle concentration in the beginning of each experiment was always below 10 particles $\mathrm{cm}^{-3}$.

A schematic of the experimental set-up is shown in Fig. 1. The particle number size distribution inside the chamber was monitored using a Scanning Mobility Particle Sizer (SMPS, 
TSI model 3080). The SMPS system used a Kr-85 neutralizer to apply a bipolar charge distribution to the aerosol particles. The SMPS was operated at a sheath flow rate of $5 \mathrm{lpm}$ and an aerosol flow rate of $1 \mathrm{lpm}$. A Vaisala HMP-233 sensor was used to monitor the relative humidity inside the bag.

Ozone was created from oxygen gas via corona discharge using an ozone generator (Azcozon) and the concentration was measured with an ozone monitor (Dasibi, 1008-PC). Ozone concentrations in the reactor ranged from $300 \mathrm{ppb}$ to $1 \mathrm{ppm}$. The ozone injected into the reactor was allowed to equilibrate for approximately $15 \mathrm{~min}$ before terpene injection. The chamber was considered to be well mixed when the ozone concentration was stable for several minutes. During some of the experiments, $0.5 \mathrm{~mL}$ of 2-butanol (SigmaAldrich, 99.5\%) was injected into the smog chamber via a gas dispersion tube in order to scavenge hydroxyl radicals produced during terpene ozonolysis (Chew and Atkinson, 1996; Keywood et al, 2004). Two types of monoterpene precursors were used in these studies. The first was $\alpha$-pinene (Sigma-Aldrich, 99+\%) and the second involved a mixture of four monoterpenes: $\beta$-pinene (Sigma-Aldrich, 99+\%), limonene (Fluka, 99+\%), 3-carene (Sigma-Aldrich, 99\%), and $\alpha$-pinene (Sigma-Aldrich, 99\%). These monoterpenes are estimated to make up the majority of global monoterpene emissions (Griffin at al., 1999). The monoterpene mixture was made before each experiment to avoid potential reactions.

The monoterpene precursor was injected into the smog chamber using a micro-liter gas-tight syringe through a septum. The reaction was conducted in the dark. A valve allowed dry, particle-free air to pass over the terpene to vaporize and transfer it to the smog chamber while some air bypassed the terpene injection point to dilute the terpene, thus reducing condensation and losses. The compressed air was passed through the injection line for less than $5 \mathrm{~min}$. A proton-transfer reaction mass spectrometer (PTR-MS, Ionicon) was used to monitor the gas phase species in the reactor. The PTR-MS is capable of on-line monitoring of volatile organic compounds at concentrations as low as a few ppt (Lindinger, 1998). The PTR-MS was operated at a drift tube voltage of $500 \mathrm{~V}$. The inlet and drift tube temperature were at $80^{\circ} \mathrm{C}$. During the first $30 \mathrm{~min}$ after terpene injection the signature of the monoterpene fragments decayed. After the concentrations of these fragments stabilized, the reaction was considered complete. Once the reaction was complete and the reactor was well-mixed, the air circulation in the temperature controlled room was turned off in order to reduce particle losses to the walls of the Teflon reactor. The experimental conditions are reported in Table 1. The reported error for the static CCN counter activation diameter is two standard deviations from the mean as measured in experiments conducted at identical supersaturations.

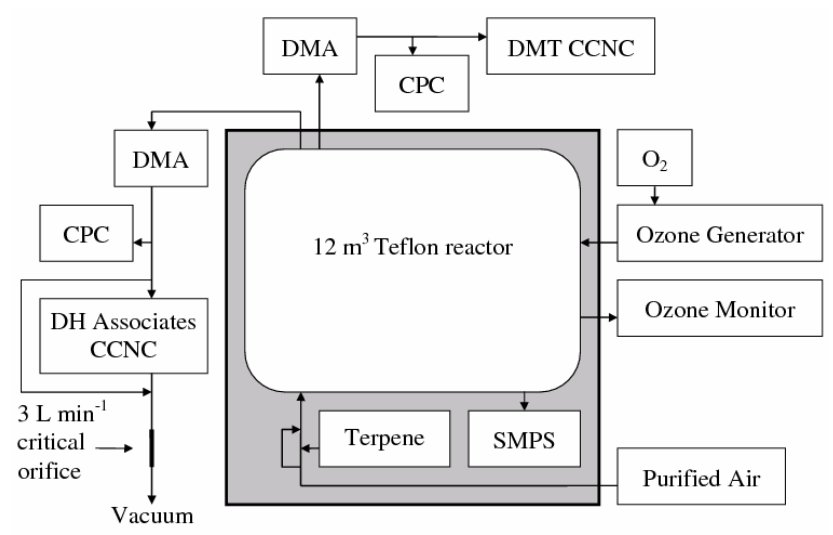

Fig. 1. Schematic of experimental set-up for monoterpene SOA formation and monitoring.

\subsection{Comparison of $\mathrm{CCN}$ instrumentation}

The CCN activity of the SOA in the reactor was measured using two CCN counters, which have fundamentally different methods for supersaturation generation. The first, a DH Associates, model M1 CCN counter, based on the "static diffusion cloud chamber" design of Twomey (1963) relies upon the nonlinear dependence of water vapor pressure upon temperature to generate supersaturation (Nenes et al., 2001). A differential mobility analyzer (DMA, TSI model 3081) was used to select a stream of nearly monodisperse particles for measurement in the static diffusion $\mathrm{CCN}$ counter. A condensation particle counter (CPC, TSI model 3010) monitored the total concentration of particles in the user-selected size. A bypass stream and a $3 \mathrm{~L} \mathrm{~min}^{-1}$ critical orifice were used to reduce disturbances due to the $\mathrm{CCN}$ counter pump filling the chamber every $30 \mathrm{~s}$. The DH Associates CCN counter measured the total number of particles that activated at a given supersaturation. The variability in activation diameter for this instrument has been reported between $15 \%$ and $20 \%$ for supersaturations between $1.0 \%$ and $0.3 \%$ (Raymond and Pandis, 2002). Two sampling strategies were used with the static $\mathrm{CCN}$ counter. The first strategy was to develop an activation curve at one supersaturation by changing the monodisperse particle diameter throughout the experiment and measuring the corresponding activated fraction. For experiments where the activation diameter was changing too rapidly, the static $\mathrm{CCN}$ counter was operated at one supersaturation and one dry particle diameter and used to monitor the change in activated fraction over time.

The second CCN counter used in this study was a Droplet Measurement Technologies (DMT) CFSTG CCN counter, which generates supersaturation by exploiting the higher diffusivity of water relative to heat (Roberts and Nenes, 2005; Lance et al., 2006). The variability of the effective supersaturation for this instrument has been measured to be as low as $\pm 1 \%$ for laboratory experiments (Rose et al., 2008). 
Table 1. Conditions for SOA Experiments.

\begin{tabular}{|c|c|c|c|c|c|c|c|}
\hline $\begin{array}{l}\text { Experiment } \\
\text { Number }\end{array}$ & $\begin{array}{c}\text { Static CCNC } \\
\text { Supersaturation } \\
(\%)\end{array}$ & $\begin{array}{l}\text { 2-Butanol } \\
\text { Use }\end{array}$ & $\begin{array}{l}\text { Initial terpene } \\
\qquad(\mathrm{ppb})\end{array}$ & $\begin{array}{l}\text { Initial Ozone } \\
(\mathrm{ppb})\end{array}$ & $\begin{array}{l}\text { Static CCNC } \\
\text { Activation Diameter } \\
(\mathrm{nm})\end{array}$ & $\begin{array}{c}\text { SMCA } \\
\text { Data }\end{array}$ & $\begin{array}{l}\text { Terpene } \\
\text { Mixture }\end{array}$ \\
\hline 1 & 0.3 & no & 16 & 300 & $104 \pm 6$ & no & $\alpha$-pinene \\
\hline 2 & 0.3 & no & 23 & 300 & $103 \pm 6$ & no & $\alpha$-pinene \\
\hline 3 & 0.3 & yes & 32 & 1000 & $98 \pm 6$ & yes & $\alpha$-pinene \\
\hline 4 & 0.6 & no & 16 & 300 & $50 \pm 14$ & no & $\alpha$-pinene \\
\hline 5 & 0.6 & no & 16 & 300 & $55 \pm 14$ & no & $\alpha$-pinene \\
\hline 6 & 0.6 & no & 16 & 300 & $63 \pm 14$ & no & $\alpha$-pinene \\
\hline 7 & 0.6 & no & 32 & 1000 & $65 \pm 14$ & yes & $\alpha$-pinene \\
\hline 8 & 1 & no & 16 & 300 & $38 \pm 3$ & no & $\alpha$-pinene \\
\hline 9 & 1 & no & 16 & 300 & $40 \pm 3$ & no & $\alpha$-pinene \\
\hline 10 & - & no & $16+47^{a}$ & 1000 & - & yes & $\alpha$-pinene \\
\hline 11 & - & no & 32 & 1000 & - & yes & $\alpha$-pinene \\
\hline 12 & 0.6 & no & 20 & 300 & $60 \pm$ & no & equal parts ${ }^{\mathrm{c}}$ \\
\hline 13 & 0.6 & no & 20 & 300 & $58 \pm 2$ & no & 2 parts carene ${ }^{c}$ \\
\hline 14 & 0.6 & no & 30 & 300 & $\mathrm{~b}$ & yes & equal parts ${ }^{c}$ \\
\hline 15 & 0.6 & no & 30 & 300 & $\mathrm{~b}$ & yes & 2 parts limonene $\mathrm{c}^{\mathrm{c}}$ \\
\hline 16 & - & no & 39 & 1000 & - & yes & equal parts ${ }^{\mathrm{c}}$ \\
\hline
\end{tabular}

a Two separate injections. The concentration after the first injection was $16 \mathrm{ppb}$ and after the second was $63 \mathrm{ppb}$.

b Static CCNC measured the CCN concentration of $100 \mathrm{~nm}$ particles at a fixed supersaturation. The static CCNC was not operated on all experiments.

c All mixtures contain $\alpha$-pinene, $\beta$-pinene, limonene and 3-carene in varying ratios. Two parts indicates twice the concentration of the indicated species in comparison to the other three monoterpenes in the mixture.

The fast time response of this instrument $(1 \mathrm{~Hz})$ allows it to be coupled with a scanning mobility particle sizer (SMPS); this technique, known as Scanning Mobility CCN Analysis (SMCA; Nenes and Medina, in review ${ }^{1}$ ) provides fast measurements of size-resolved $\mathrm{CCN}$ activity and droplet growth kinetics. In our measurements, a TSI 3080 SMPS, composed of a condensation particle counter (CPC, TSI 3010) and a differential mobility analyzer (DMA, TSI 3081) classified and measured the dry particle size distribution. Dried aerosol was charged using a $\mathrm{Kr}-85$ neutralizer (TSI 3077A) and introduced into the DMA during which particles were classified by electrical mobility and counted by the CPC and $\mathrm{CCN}$ counter as the voltages at the DMA was scanned. A complete CCN "activation curve" (or ratio of CCN/CN over a wide range of sizes and supersaturation) was then obtained in each DMA upscan-downscan cycle. The downscan of the DMA voltage is short, about $1 / 8$ the time used for the voltage upscan; this generates a peak response in both CPC and CCN counters, which is then used to align the response timeseries of both detectors. The activation curve is then obtained by inverting the timeseries to obtain number and $\mathrm{CCN}$ size distributions. Multiple supersaturations were cycled through the duration of each experiment in the DMT CCN counter. The

\footnotetext{
${ }^{1}$ Nenes, A. and Medina, J.: Scanning Mobility CCN Analysis: a method for fast measurements of size-resolved CCN activity and growth kinetics, Aeros. Sci. Tech., in review, 2008.
}

DMT CFSTG CCN counter has the capability to change supersaturations much faster than the static $\mathrm{CCN}$ counter due to its control system and alternative method for generating supersaturation (Roberts and Nenes, 2005). A change in supersaturation can be achieved in approximately $0.5-3.5 \mathrm{~min}$ (Rose et al., 2008).

The activated fraction, $f_{\text {act }}$, of SOA is calculated dividing the $\mathrm{CCN}$ concentration by the total particle concentration measured by the CPC. The concentration versus $f_{\text {act }}$ data is then fit to a sigmoidal curve:

$f_{\text {act }}=\frac{a}{1+\exp \left(-\left(d_{p}-D_{50}\right) / b\right)}$

where $d_{p}$ is the dry particle diameter, $a$ is the fraction activated at large particle diameters, $b$ is a size distribution width parameter, and $D_{50}$ is the activation diameter, which is calculated as the particle diameter corresponding to $50 \%$ of the height of the sigmoid.

The sigmoidal fit neglects the multiply charged particles, which activate early and thus form a hump in the fraction activated versus mobility diameter (Fig. 2). The impact of the multiply charged particles was estimated using a method similar to that described in Petters et al. (2007) using as basis the measured size distribution in the smog chamber. The equivalent mobility diameters of the multiply charged particles associated with each diameter of interest were calculated. Special attention was paid to the calculated activation 


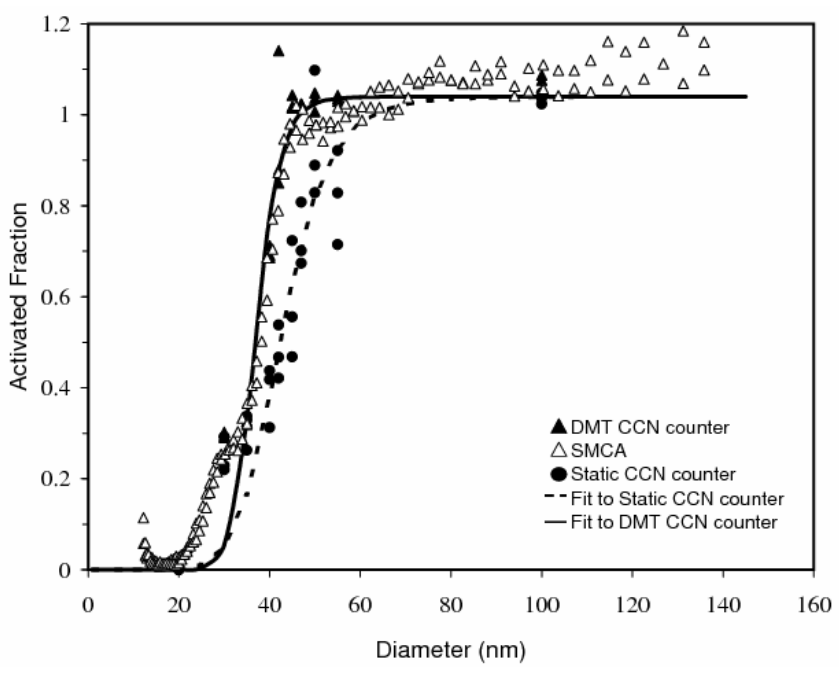

Fig. 2. Activated fraction versus mobility diameter for ammonium sulfate at $0.6 \%$ supersaturation. Triangular symbols are for data from the DMT CCN counter and circular symbols are for the DH Associates CCN counter. Filled symbols are for the slow counting method typically used only for the static CCN counter. The open symbols are recorded for the DMT CCN counter coupled with an SMPS to operate as a SMCA. The dashed line indicates the fit to the static CCN counter data and the solid line indicates the fit to the DMT CCN counter data.

diameters. Using charging theory the fraction of particles at a given size bin with $+1,+2$ and +3 charges was determined, which was then multiplied by the number of particles at the associated diameters. The sum of the multiply charged particles divided by the total number of charged particles gives the approximate fractional error at the investigated diameter. Based upon this fractional error at the activation diameter or for the entire range of $\mathrm{CCN}$ data points a multiple-charge corrected activation diameter was estimated by shifting the activation curve and alternatively by refitting the $\mathrm{CCN}$ activation curve to the revised activities. The estimated error was less than $15 \%$ for all experiments and is included in the estimated uncertainty of our measurements discussed in a subsequent section. Therefore, no correction was made for multiply charged particles entering the DMA for the static CCN counter as the adjustment in the fit due to multiply charged particles is within the reported uncertainty of the instrument (Raymond and Pandis, 2002). The shape of the aerosol size distribution after the completion of the reactions remains relatively constant and therefore the error due to the multiple charging also remains practically constant.

The static CCN counter can measure one $f_{\text {act }}$ every $7.5 \mathrm{~min}$. To measure an activation curve spanning the diameters of interest requires several hours of data collection. Due to long equilibration times required to change supersaturations in the cloud chamber and the continuous loss of particles to the walls of the smog chamber over the course of
Table 2. $\sigma$ values inferred at the point of activation.

\begin{tabular}{|c|c|c|}
\hline Sample & $\begin{array}{c}\sigma \\
\left(\mathrm{mN} \mathrm{m}^{-1}\right)\end{array}$ & $\begin{array}{c} \pm \Delta \sigma \\
\left(\mathrm{mN} \mathrm{m}^{-1}\right)\end{array}$ \\
\hline $\begin{array}{l}\alpha \text {-pinene SOA with } \\
90 \%\left(\mathrm{NH}_{4}\right)_{2} \mathrm{SO}_{4}\end{array}$ & 61.7 & 1.9 \\
\hline $\begin{array}{l}\alpha \text {-pinene SOA with } \\
95 \%\left(\mathrm{NH}_{4}\right)_{2} \mathrm{SO}_{4}\end{array}$ & 65.8 & 3.0 \\
\hline $\begin{array}{l}\text { Mixed Monoterpene } \\
\text { SOA with } \\
95 \%\left(\mathrm{NH}_{4}\right)_{2} \mathrm{SO}_{4}\end{array}$ & 66.5 & 1.5 \\
\hline
\end{tabular}

5-10 h of measurement the instrument can reliably obtain one $\mathrm{CCN}$ activation curve at one supersaturation during one chamber experiment.

For instrument comparison, the two $\mathrm{CCN}$ counters were both operated with the 7.5 min per diameter sampling strategy typically used for the static CCN counter. The sample flow from the DMA was split between the static CCN counter, the CFSTG CCN counter and the CPC. Since the CFSTG CCN counter is able to discern small changes in activation diameter an average over the experiment is calculated and the error bars reported are two standard deviations from the mean. The instruments compared well in their measurements of model aerosol systems. Comparison studies of ammonium sulfate particles showed that both instruments measured within $2 \mathrm{~nm}$ of classical Köhler theory predictions assuming complete solubility, surface tension of water, a molecular weight of $132 \mathrm{~g} \mathrm{~mol}^{-1}$, and a dry density of $1.77 \mathrm{~g} \mathrm{~mol}^{-1}$ at $0.6 \%$ supersaturation (Fig. 2). The static $\mathrm{CCN}$ counter was measuring a slightly higher activation diameter than predicted, while the CFSTG CCN counter was measuring slightly below the prediction.

After the consistency of the two instruments was established with ammonium sulfate, the instruments were used to monitor SOA particles generated in the smog chamber. The static CCN counter activation diameters for each $\alpha$-pinene and mixed monoterpene experiment are reported in Table 1. SMCA was used to monitor the evolution of the SOA activation diameter in experiments $3,7,10,11,14,15$ and 17 (Table 1).

\subsection{Filter sample extraction and analysis}

For experiments 11 and 16 (Table 1), SOA from $\alpha$-pinene and mixed monoterpene precursors was collected upon Teflon filters. Similarly to Asa-Awuku et al. (2007a) and Sullivan and Weber (2006), the SOA filter samples were subsequently extracted in water during a $1.25 \mathrm{~h}$ sonication process with heat (water bath temperature is approximately $60^{\circ} \mathrm{C}$ ). The WSOC concentration was then measured with a Sievers 900 Portable 


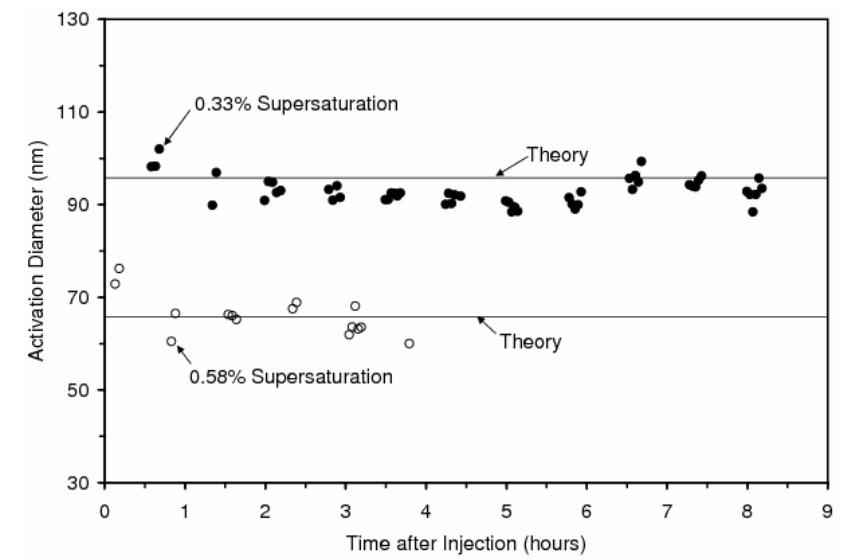

Fig. 3. Activation diameter versus time from reaction initiation for experiment 3 with hydroxyl radical scavenger as measured with SMCA. The theory lines correspond to classical Köhler theory with molecular weight of $180 \mathrm{~g} \mathrm{~mol}^{-1}$, particle density of $1.5 \mathrm{~g} \mathrm{~cm}^{-3}$, no dissociation, and the surface tension of water.

Total Organic Carbon (TOC) Turbo analyzer and found to be $12 \mathrm{mg} C \mathrm{~L}^{-1}$ in both extracts (for a total of around $200 \mu \mathrm{g}$ of WSOC per filter). The experimental set-up used to measure CCN activity of WSOC extracted from the filter samples is identical to those used in Padró et al. (2007) and Asa-Awuku et. al. (2007a; 2007b). 3-5 ml of extracted sample was atomized in a collision type atomizer, dried with two diffusional driers and subsequently characterized with SMCA. The classified aerosol was then activated into droplets using the DMT CCN Counter.

\section{Results}

\subsection{Aging of SOA particles}

One $\alpha$-pinene experiment, experiment 3, used 2-butanol as a hydroxyl radical scavenger during SOA generation. Figure 3 shows the change in activation diameter versus time from injection for that experiment for 0.33 and $0.58 \%$ supersaturation for up to nine hours. The theory lines show calculations from "classical" Köhler theory with the assumptions of a molecular weight of $180 \mathrm{~g} \mathrm{~mol}^{-1}$, the surface tension of water and a density of $1.5 \mathrm{~g} \mathrm{~mol}^{-1}$. These predictions are quite close to the average diameters for the experiment, which are $66 \mathrm{~nm}$ for $0.58 \%$ supersaturation and $93 \mathrm{~nm}$ for $0.33 \%$ supersaturation. Measurements taken during the first $30 \mathrm{~min}$ of experiment 3, which is during the ozonolysis reaction, indicate slightly higher activation diameters than later measurements. This period of the experiment is also marked by higher uncertainties due to the condensing gases and developing size distribution. After the first $30 \mathrm{~min}$ there is no statistically significant change, at the $95 \%$ confidence level, in activation diameter for the supersaturations measured $(0.33$ and $0.58 \%$ ). During the first $30 \mathrm{~min}$ the activation diame-

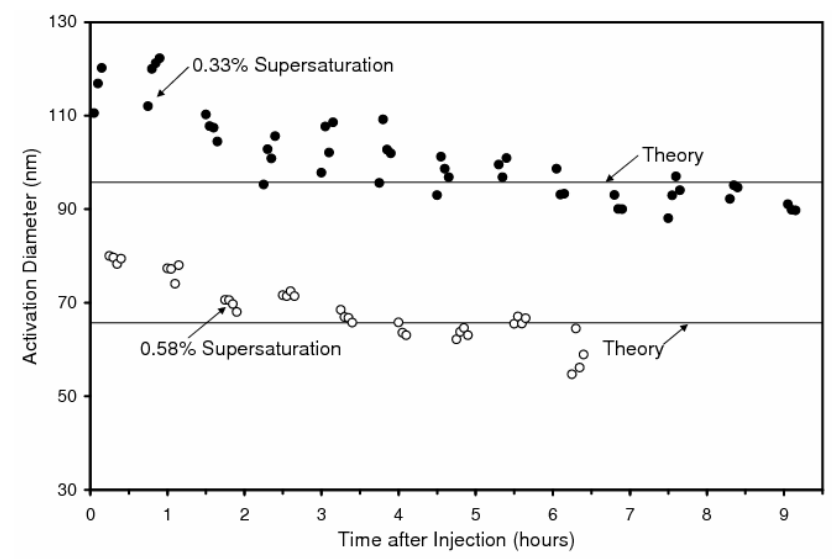

Fig. 4. Activation diameter versus time from reaction initiation for experiment 7 without hydroxyl radical scavenger as measured with SMCA. The theory lines correspond to classical Köhler theory with molecular weight of $180 \mathrm{~g} \mathrm{~mol}^{-1}$, particle density of $1.5 \mathrm{~g} \mathrm{~cm}^{-3}$, no dissociation, and the surface tension of water.

ter is likely changing due to the condensation of species with different activation properties and not necessarily particle aging.

For experiment 7 identical conditions to experiment 3 were used, but without the hydroxyl radical scavenger; results are shown in Fig. 4. In experiment 7, fresh particles appear less $\mathrm{CCN}$ active than those produced in the absence of $\mathrm{OH}$ in experiment 3. The activation diameter decreased at approximately $3 \mathrm{~nm} \mathrm{~h}^{-1}$ for $0.33 \%$ and $0.58 \%$ supersaturation for the first few hours. After four hours of reaction, the activation diameter approached that of experiment $3(66 \mathrm{~nm}$ for $0.58 \%$ supersaturation and $93 \mathrm{~nm}$ for $0.33 \%$ supersaturation). The classical Köhler theory lines are shown for reference.

A potential explanation for the reduced $\mathrm{CCN}$ activity is that the reaction of $\alpha$-pinene with hydroxyl radicals produces a higher fraction of pinonaldehyde in the reaction products than the ozonolysis of $\alpha$-pinene (Nozière et al., 1999; Jang and Kamens, 1999). The reduced fraction of carboxylic acids as compared to aldehydes could decrease the amount of water-soluble material available and therefore may be the cause of the reduced activity in the presence of the competing hydroxyl radical reaction with the monoterpenes.

The ozone concentrations in the reactor ranged from 300$1000 \mathrm{ppb}$. Assuming an average atmospheric concentration of $40 \mathrm{ppb}$ ozone this would correspond to an ozone exposure equivalence of approximately 2 days of atmospheric aging. A rough estimate of hydroxyl radical concentrations based on the decay of 2-butanol as measured by the PTR-MS was $2 \times 10^{6}$ molecules $\mathrm{cm}^{-3}$. This is roughly equivalent to daytime hydroxyl radical concentrations in the troposphere.

The effect of the hydroxyl radicals on particle aging and $\mathrm{CCN}$ activity is not limited to $\alpha$-pinene SOA, but was also observed in the mixed monoterpene ozonolysis experiments. 


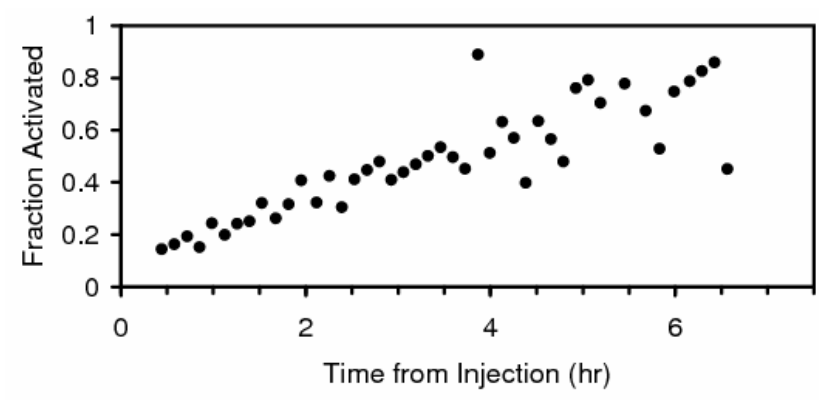

Fig. 5. Aging of $55 \mathrm{~nm}$ mixed monoterpene (equal parts $\alpha$-pinene, $\beta$-pinene, limonene and 3-carene) SOA particles at $0.6 \%$ supersaturation (experiment 14) measured with the static $\mathrm{CCN}$ counter.

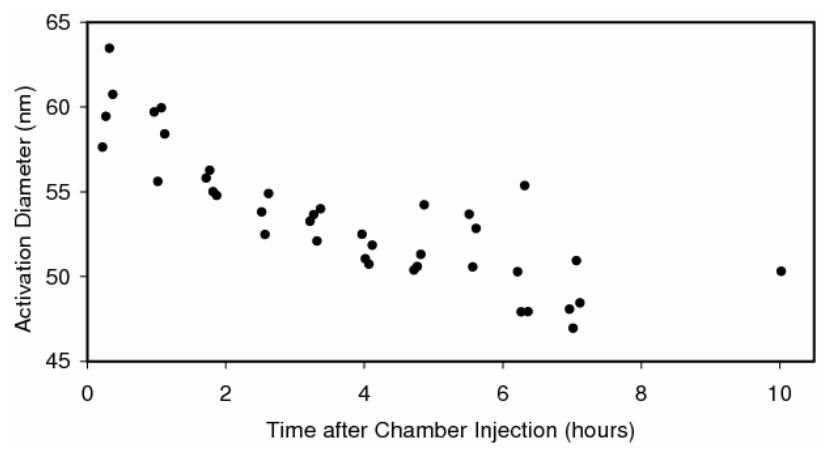

Fig. 6. Evolution of activation diameter (obtained with SMCA) with time from injection at $0.74 \%$ supersaturation for an equal parts mixture of $\alpha$-pinene, $\beta$-pinene, limonene, and 3-carene (experiment 14).

The static CCN counter is able to observe changes in activation diameter due to aging if it is operated at a constant supersaturation and supplied with a stream of monodisperse particles of constant diameter. Figure 5 shows the change in activated fraction for $55 \mathrm{~nm}$ dry diameter particles in the mixed monoterpene SOA produced in experiment 14 as measured by the static CCN counter. Due to the inherent challenge of particle loss to the walls in chamber studies the uncertainty increases later in the experiment and, therefore, the activated fraction (Fig. 5) becomes more variable. Experiment 14 did not include 2-butanol to scavenge hydroxyl radicals produced in the ozonolysis. The fraction of $55 \mathrm{~nm}$ particles that were $\mathrm{CCN}$ active increased at an initial rate of $0.1 \mathrm{~h}^{-1}$. This effect can also be seen in the activation diameter; Fig. 6 shows the evolution of $D_{50}$ (measured with SMCA) at $0.74 \%$ supersaturation for the mixed monoterpene SOA produced in experiment 14 . The activation diameter is decreasing, on average, at a rate of $1.6 \mathrm{~nm} \mathrm{~h}^{-1}$. After $4.5 \mathrm{~h}$, the data in Figs. 3 and 5 are consistent with a zero slope, which would indicate that the particle aging stopped or was reduced to a negligible rate. This leveling off of activation diameter is highlighted by the final data point in Fig. 6, which was recorded at approximately $10 \mathrm{~h}$; the SOA had roughly the same $\mathrm{CCN}$ acti-

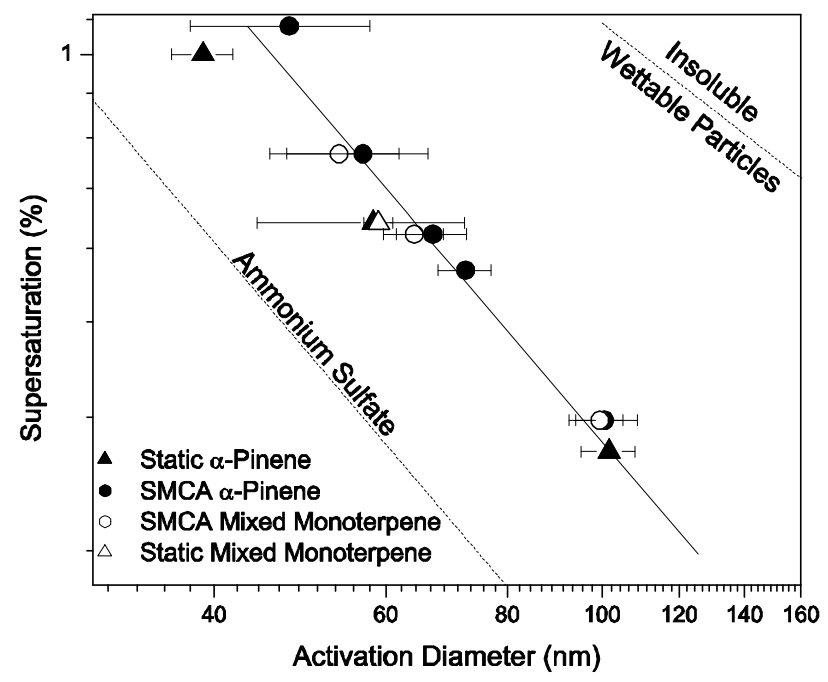

Fig. 7. Critical supersaturation versus measured activation diameter of $\alpha$-pinene and mixed monoterpene SOA for SMCA (circles) and the static CCN counter (triangles). Köhler theory predictions are shown as a black line for classical theory with molecular weight of $180 \mathrm{~g} \mathrm{~mol}^{-1}$, particle density of $1.5 \mathrm{~g} \mathrm{~cm}^{-3}$, no dissociation, and the surface tension of water. The error bars reflect two standard deviations from the mean. The dashed lines are shown as bounds for CCN activation diameter of ammonium sulfate (lower bound) and insoluble, wettable particles (upper bound).

vation as particles measured $2.5 \mathrm{~h}$ previously. Even though these changes in activation diameter are clearly observable, they are modest compared to the differences in activation diameter for different SOA precursors (Huff-Hartz et al., 2005; Asa-Awuku et al., 2008). For example, at $1 \%$ supersaturation, the reported average $D_{50}$ is equal to $120 \mathrm{~nm}$ and $48 \mathrm{~nm}$ for sesquiterpene and monoterpene aerosol, respectively.

\subsection{Potential of SOA as CCN}

The initial concentration of $\alpha$-pinene, the monoterpene mixtures, and ozone do not appear to affect the activation diameter of the resulting SOA (within the $10-40 \mathrm{ppb}$ range). For example, experiments 1 and 3 were conducted at 16 and $32 \mathrm{ppb} \alpha$-pinene and 300 and $1000 \mathrm{ppb}$ ozone, respectively. The static CCN counter activation diameters for these two experiments differ by less than 7\%. Previous work with this static CCN counter reports $17 \%$ uncertainty for experiments performed at $1 \%$ supersaturation and $20 \%$ for experiments performed at $0.3 \%$ supersaturation (Raymond and Pandis, 2002). Hence, any small changes due to initial concentrations of ozone or terpene are within experimental error. Therefore, all activation diameters measured at a given supersaturation are averaged, regardless of precursor concentration. 
The average activation diameters versus supersaturation for $\alpha$-pinene and mixed monoterpenes are shown in Fig. 7. The data reported are an average of all experiments conducted at $0.3,0.33,0.52,0.58,0.6,0.74,1.0$, and $1.09 \%$ supersaturation. The measurements of SOA CCN activity for both instruments were consistent within experimental error. Also, the CCN activity data from $\alpha$-pinene SOA is virtually indistinguishable from SOA produced from a mixture of monoterpenes. The particles are reasonably active as $\mathrm{CCN}$ when contrasted against ammonium sulfate and insoluble, wettable particles. The error bars indicate two standard deviations from the mean $\mathrm{CCN}$ activation diameter. These error bars reflect standard experimental uncertainties as well as the modest shift in activation diameter observed in the presence of hydroxyl radicals.

\subsection{Köhler theory analysis of SOA}

Köhler theory (Köhler, 1936) is used to link the observed CCN activity with SOA composition and size; thermodynamic arguments are used to describe the balance of two effects on the water vapor pressure over a wet particle. The Kelvin, or curvature, effect tends to increase the equilibrium vapor pressure above a droplet relative to a flat surface because fewer intermolecular forces hold an individual water molecule in the droplet. Conversely, the Raoult, or solute, effect tends to decrease the vapor pressure relative to a flat surface from dissolved compounds.

Köhler Theory Analysis (KTA) (Asa-Awuku et al., 2007a, b; Padró et al., 2007) is derived from Köhler theory and utilizes CCN measurements to infer average molar volume (molecular weight, $M$, over density $\rho$ ) of the water-soluble organic fraction of the SOA. KTA (method $b_{1}$, Padró et al., 2007) employs measurements of the activation diameter, $D_{50}$, versus critical supersaturation, $s_{c}$; these quantities are then fit to the expression,

$s_{c}=\omega D_{50}-3 / 2$

to obtain the Fitted CCN Activation (FCA) parameter, $\omega$. If all parameters, including surface tension, are known, $\omega$ can be used to obtain $\frac{M}{\rho}$,

$$
\frac{M}{\rho}=\frac{\varepsilon v}{\frac{256}{27}\left(\frac{M_{w}}{\rho_{w}}\right)^{2}\left(\frac{1}{R T}\right)^{3} \sigma^{3} \omega^{-2}}
$$

where $\rho$ is density of the SOA, $M$ is the average molecular weight of the SOA, $M_{w}$ is the molecular weight of water, $\rho_{w}$ is the water density, $\sigma$ is the air-drop surface tension, $\varepsilon$ is the WSOC volume fraction, $v$ is the effective van't Hoff factor, $T$ is the ambient temperature, and $R$ is the universal gas constant.

Often, like in this work, the concentration of WSOC extracted from filters is low (less than $100 \mathrm{ppm}$ ) so direct measurements of surface tension are not representative of (or cannot be reliably extrapolated to) the conditions at activation. To address this the surface tension depression method of Asa-Awuku et al. (2007a) is used. The method involves:

i) measuring the $\mathrm{CCN}$ activity of atomized aerosol generated from a mixture of the extracted WSOC and ammonium sulfate, and,

ii) using Köhler theory, and the known composition (ammonium sulfate versus WSOC) of the aerosol samples to infer the surface tension required to reproduce the $\mathrm{CCN}$ activity of the samples.

The inferred surface tension is calculated as follows (AsaAwuku et al., 2007a)

$\sigma=\sigma_{w}\left(\frac{s_{c}}{s_{c} *}\right)^{2 / 3}$

where $s_{c}$ is an experimental value of critical supersaturation, $s_{c} *$ is the critical supersaturation predicted using Köhler theory assuming the value of water surface tension, $\sigma_{w}$, and $\sigma$ is the air-water surface tension of the $\mathrm{CCN}$ at the critical point. The mass of organic carbon, necessary to infer $\sigma$, in the extracted sample is determined by multiplying the measured WSOC carbon concentration by an organic mass-to-carbon ratio of 2 (Asa-Awuku et al., 2007a). Since both the molecular weight of the SOA and the surface tension of the droplets are unknown, Eqs. (2) and (3) are solved simultaneously to find the optimum value for $M$ and $\sigma$. In this work the optimum value of $M$ was found to be $180 \mathrm{~g} \mathrm{~mol}^{-1}$.

In applying KTA for the WSOC extracts, we assume complete solubility, $\varepsilon=1$ and an effective organic van't Hoff factor, $v=1$. Molecular weights are estimated assuming an average organic density of $1.5 \mathrm{~g} \mathrm{~cm}^{-3}$ (Kostenidou et al., 2007). The uncertainty in inferred molar volume can be computed as

$\Delta\left(\frac{M}{\rho}\right)=\sqrt{\sum_{\text {for all } x}\left(\Phi_{x} \Delta x\right)^{2}}$,

where $\Delta x$ is the uncertainty in of each of the measured parameters $x$, (i.e., $\sigma, \omega$, and $v$ ) and $\Phi_{x}=\frac{\partial}{\partial x}\left(\frac{M}{\rho}\right)$ is the sensitivity of molar volume to $x$. Formulae for molar volume sensitivity calculations are reported elsewhere (Asa-Awuku et al, 2007a, Asa-Awuku et al., 2007b; Padró et al., 2007).

For our studies, we employ KTA to estimate molecular weight of SOA from the online measurements assuming all of the aerosol is soluble (Fig. 8). KTA suggests that the molecular weight of the SOA drops significantly within the first hour of the experiment. However, significant changes in composition are not observed in the AMS data (not presented here). These large changes from KTA estimates may also reflect changes in solubility rather than changes in molar mass. Consequently the results of Fig. 8 suggest that 


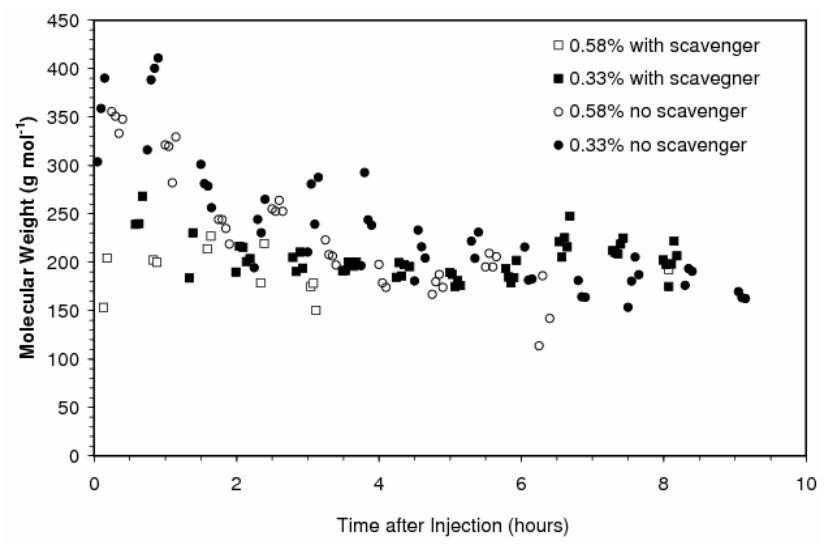

Fig. 8. Apparent $\alpha$-pinene SOA molecular weight versus time obtained with KTA assuming $\varepsilon=1$. Square symbols are for experiment 3 , and circular symbols are for experiment 7, $\alpha$-pinene precursor with and without hydroxyl radical scavenger. Molecular weight is estimated using $\sigma=72 \mathrm{mN} \mathrm{m}^{-1}$.

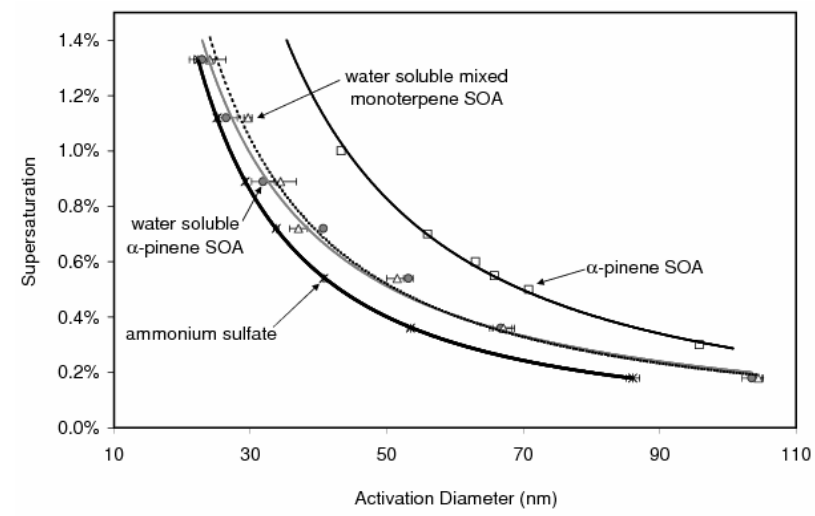

Fig. 9. CCN Activity of water soluble SOA generated from $\alpha$ pinene and mixed monoterpene ozonolysis. Water soluble $\alpha$-Pinene SOA is represented by circles and mixed monoterpene SOA by triangles. Köhler Theory is used to predict the CCN activity of the offline components based on reported average online molecular weight values, $180 \mathrm{~g} \mathrm{~mol}^{-1}$, and the surface tension of water. Online measurements of $\alpha$-pinene SOA and $\left(\mathrm{NH}_{4}\right)_{2} \mathrm{SO}_{4}$ are shown for comparison.

a) the aerosol is composed of insoluble and soluble fractions which after the first hour transitions into the "asymptotic composition", or

b) the aerosol is semi-volatile and requires half an hour to become "thermally stable" in the CFSTG instrument (operated at $\sim 35^{\circ} \mathrm{C}$ ).

The first hypothesis can be investigated by comparing the $\mathrm{CCN}$ activity of the extracted samples versus the online SOA. The second hypothesis is unlikely, as the AMS spectra do not show compositional changes throughout the duration of the experiment. As with online measurements, the offline $\alpha$ -

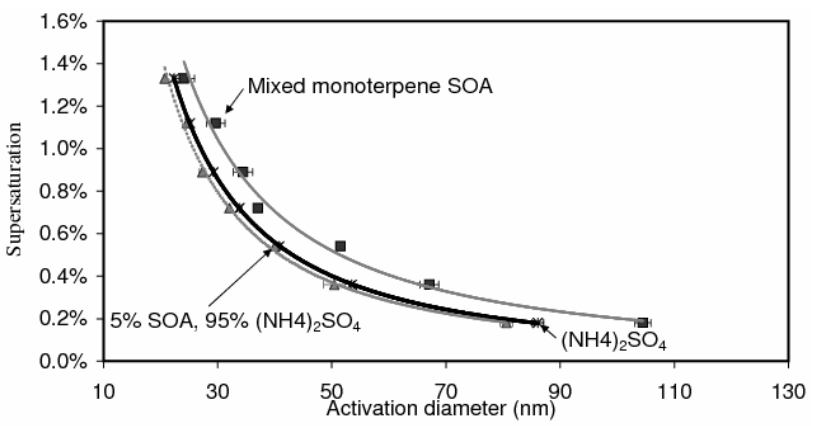

Fig. 10. CCN activity of WSOC generated from ozonolysis of mixed monoterpenes filter samples. Results are shown for pure water soluble mixed monoterpene SOA and mixtures of $\left(\mathrm{NH}_{4}\right)_{2} \mathrm{SO}_{4}$ and water soluble mixed monoterpene SOA.

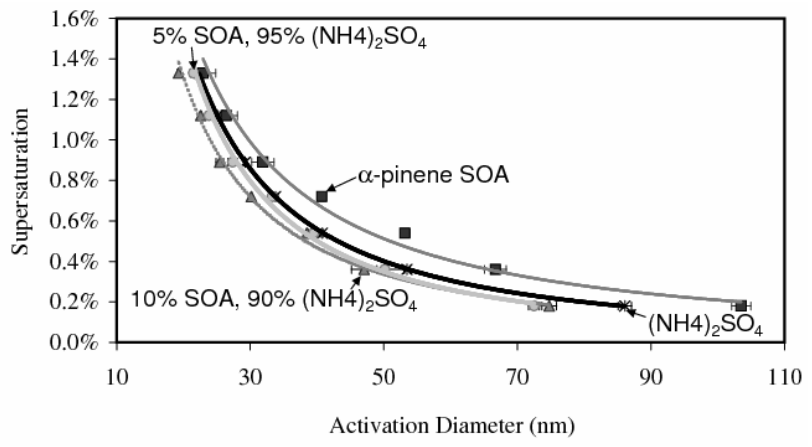

Fig. 11. CCN activity of WSOC generated from ozonolysis of $\alpha$ pinene filter samples. Results are shown for pure WSOC and mixtures of $\left(\mathrm{NH}_{4}\right)_{2} \mathrm{SO}_{4}$.

pinene and mixed monoterpene filter SOA have similar activity (Fig. 9). A comparison of the online smog chamber samples (Fig. 9) to water soluble SOA filter samples reveals the offline samples are much more CCN active SOA than their online counterparts. This suggests that only a fraction of the SOA in these experiments dissolves in water. Subsequently $\left(\mathrm{NH}_{4}\right)_{2} \mathrm{SO}_{4}$ was added to the water-soluble components of the $\alpha$-pinene and mixed monoterpene SOA (Figs. 10 and 11). The increase in soluble material enhances the $\mathrm{CCN}$ activity; from these measurements $\sigma$ can be inferred (Eq. 2) and are reported in Table 2. Other KTA properties for the WSOC are given in Table 3. The greatest surface tension depression observed is for samples containing $10 \%$ water soluble $\alpha$-pinene SOA and $90 \%$ ammonium sulfate. Measurements have indicated that $\alpha$-pinene and mixed monoterpene SOA have similar water-soluble organic components (Fig. 9) and hence it is also inferred that the greatest surface tension depression for the $\alpha$-pinene and mixed monoterpene species is $61.7 \pm 1.9 \mathrm{mN} \mathrm{m}^{-1}$. Assuming that the surface tension of the water-soluble component can be applied to the soluble component of the online aerosol, the soluble fraction at the "asymptotic composition" is estimated to be $\sim 65 \%$ (Fig. 12). 


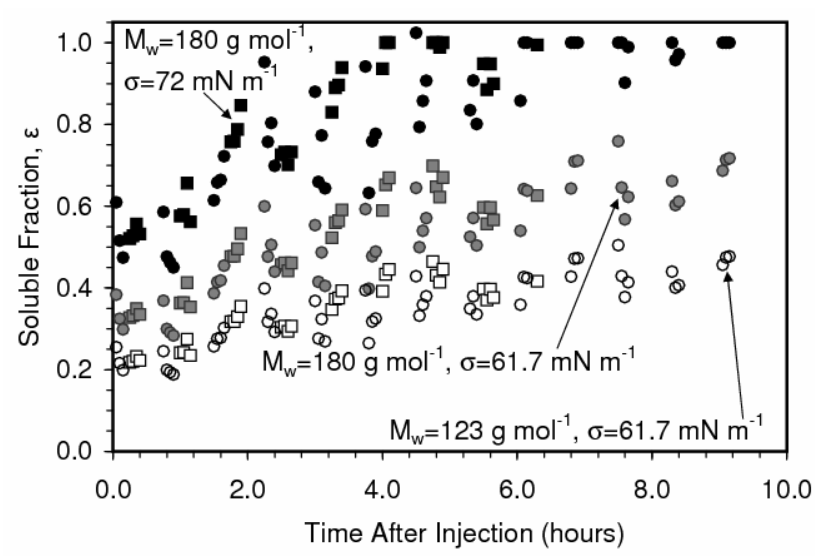

Fig. 12. Soluble fraction of $\alpha$-pinene SOA inferred from offline measurements.

\subsection{Droplet growth kinetics}

In addition to $\mathrm{CCN}$ measurements, the optical particle counter of the DMT CFSTG CCN counter measures droplet sizes and therefore can be used to explore the impact of organics on droplet growth kinetics. When exposed to the same supersaturation profile, an activated CCN will grow to cloud droplets of similar wet diameter, $D_{p}$, provided that the mass transfer coefficient of water vapor to the growing droplet and the critical supersaturation is the same. The impact of organics on CCN growth kinetics for our samples is assessed by comparing the wet diameter, $D_{p}$, of activated SOA particles with activated $\left(\mathrm{NH}_{4}\right)_{2} \mathrm{SO}_{4}$ particles at given instrument supersaturations. The ammonium sulfate particles represent a well-studied inorganic system for comparison. The dry particles used in the comparison had a critical supersaturation equal to the instrument supersaturation, $s$, which means that the dry diameter was equal to the activation diameter. The flow rates in these measurements are maintained constant, as changes would affect the residence time (and resulting $D_{p}$ ) in the instrument.

The droplet diameters of activated SOA obtained online do not significantly change over time for mixed monoterpene and $\alpha$-pinene SOA. Wet diameters measured of SOA from the filter samples are consistent with values obtained from online measurements except for the lowest supersaturation where online aerosol grows more slowly than offline (Fig. 13). The agreement of online and offline SOA measurements with ammonium sulfate particle growth (with the exception of low supersaturations measured online) indicates that organics in the $\alpha$-pinene and mixed monoterpene SOA do not further impact the droplet growth kinetics. For all salted and non-salted SOA filter samples, the droplet growth is similar to $\left(\mathrm{NH}_{4}\right)_{2} \mathrm{SO}_{4}$ (Fig. 13).

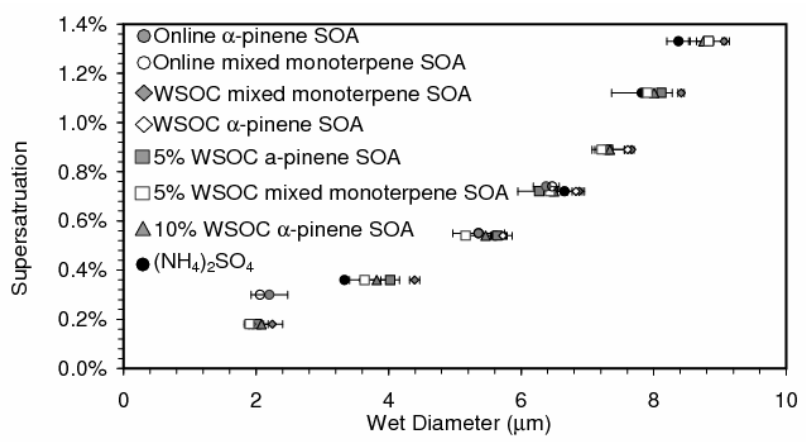

Fig. 13. Growth kinetics of $\mathrm{SOA}$ and $\left(\mathrm{NH}_{4}\right)_{2} \mathrm{SO}_{4}$. Dark grey symbols are for $\alpha$-pinene SOA and open symbols are for mixed monoterpene SOA. Mixtures are SOA of the stated percentage with the balance of ammonium sulfate.

\section{Parameterization using “classical” Köhler theory}

Köhler Theory Analysis is a powerful tool to elucidate detailed information from experimental results and thus increases our understanding of the interactions of SOA with water. However, KTA requires more information than is often available for ambient systems and thus for large-scale chemical transport models.

Köhler theory can be used to calculate the activation diameter (i.e. the dry particle diameter that has a given critical supersaturation) once values for molecular weight, surface tension, van't Hoff factor and solubility are assumed. KTA gives a comprehensive picture of these thermodynamic properties, but different combinations (even if inherently incorrect) of parameters may give the same $\mathrm{CCN}$ activity. The later is what we term "classical" Köhler theory parameterization of the SOA. For this, the air-drop surface tension is assumed to be that of pure water and the SOA material is assumed to be completely soluble in water at the activation point with no dissociation. The particle density is assumed to be $1.5 \mathrm{~g} \mathrm{~cm}^{-3}$ based on the measurements of Kostenidou et al. (2007) for these systems. Two approaches can be taken for constraining the average molecular weight, $x$, of the monoterpene:

i) using the weighted average $\left(175 \mathrm{~g} \mathrm{~mol}^{-1}\right)$ of the speciated compounds from chemical analysis of SOA (HuffHartz et al., 2005), or

ii) Köhler Theory Analysis (KTA) (Asa-Awuku et al., 2007a, b; Padró et al., 2007).

Since both methods, within error, are in agreement the value from KTA will be used. The experimental measurements of the CCN activity of $\alpha$-pinene SOA are similar to activation diameters estimated from classical Köhler theory. Figure 14 shows the comparison of activation diameters measured with the static CCN counter and SMCA versus activation diameters predicted from Köhler theory (assuming an aged SOA composition) for all experiments of pinene and 
Table 3. Köhler theory analysis properties and molar volume results for filter samples.

\begin{tabular}{lll}
\hline Property (units) & $\alpha$-pinene & Mixed Monoterpenes \\
\hline FCA,$\omega\left(\mathrm{m}^{1.5}\right)$ & $5.61 \times 10^{-14}$ & $5.55 \times 10^{-14}$ \\
$\left.\sigma(\mathrm{N} \mathrm{m})^{-1}\right)^{\mathrm{d}}$ & $61.7 \times 10^{-2}$ & $61.7 \times 10^{-2}$ \\
$\left(\frac{M}{\rho}\right)\left(\mathrm{m}^{3} \mathrm{~mol}^{-1}\right)^{\mathrm{d}}$ & $8.18 \times 10^{-5}$ & $8.36 \times 10^{-5}$ \\
$M\left(\mathrm{~g} \mathrm{~mol}^{-1}\right)^{\mathrm{e}}$ & $122^{\mathrm{d}}(77)^{\mathrm{f}}$ & $125^{\mathrm{d}}(79)^{\mathrm{f}}$ \\
\hline
\end{tabular}

$\mathrm{d}$ inferred from activation experiments assuming $\alpha$-pinene and the mixed monoterpenes have similar organic surface active components and surface tension depression at droplet activation.

e Assuming the density of the solute is $1500 \mathrm{~kg} \mathrm{~m}^{-3}$ (Kostenidou et al., 2007).

${ }^{\mathrm{f}}$ KTA results based on $\sigma=\sigma_{\text {water }}\left(72 \mathrm{~N} \mathrm{~m}^{-1}\right)$.

mixed monoterpene SOA. Within uncertainty, all of the data points fall on the 1:1 line demonstrating that the behavior of $\alpha$-pinene and mixed monoterpene SOA can be modeled with classical Köhler theory, assuming a common composition. An important outcome is that apparent closure with observed CCN activity, however good it may be, may not necessarily imply understanding of CCN properties.

One limitation of this classical Köhler theory parameterization is that its explicit statement of all variables makes intercomparison between studies somewhat cumbersome with details. Petters and Kreidenweis (2006) introduced $\kappa$, a parameter to quantitatively compare $\mathrm{CCN}$ activity, which allows for a quick comparison of similar studies. The measurements in this study are generally consistent with the measurements of Prenni et al. (2007). Prenni et at. (2007) reported $\kappa$ values of $0.1 \pm 0.04$ for $\alpha$-pinene, $\beta$-pinene, and 3 -carene SOA. In this study we found $\kappa$ values ranging between 0.14 and 0.23 for the static $\mathrm{CCN}$ counter and 0.11 and 0.14 for the DMT CCN counter for $\alpha$-pinene and mixed monoterpene SOA. The larger range in $\kappa$ values is expected for the static CCN counter due to larger uncertainty in the measurements. The observations of Huff Hartz et al. (2005) at $0.3 \%$ and $1.0 \%$ supersaturation are also generally consistent with $\kappa$ values ranging between 0.04 and 0.12 and 0.09 and 0.24 , respectively. The measurements of VanReken et al. (2005) and Huff Hartz et al. (2005) both show a higher $\kappa$ value than observed in this study.

\section{Conclusions}

The CCN activity of SOA generated by the ozonolysis of $\alpha$ pinene and mixed monoterpenes has been measured using a static CCN counter and a Scanning Mobility CCN Analyzer (SMCA). We do not see a statistically significant decrease in particle activation diameter of $\alpha$-pinene SOA if hydroxyl radicals are scavenged from the experimental system by 2 butanol. In the presence of hydroxyl radicals, the $\alpha$-pinene SOA is initially less CCN active than expected for aged SOA,

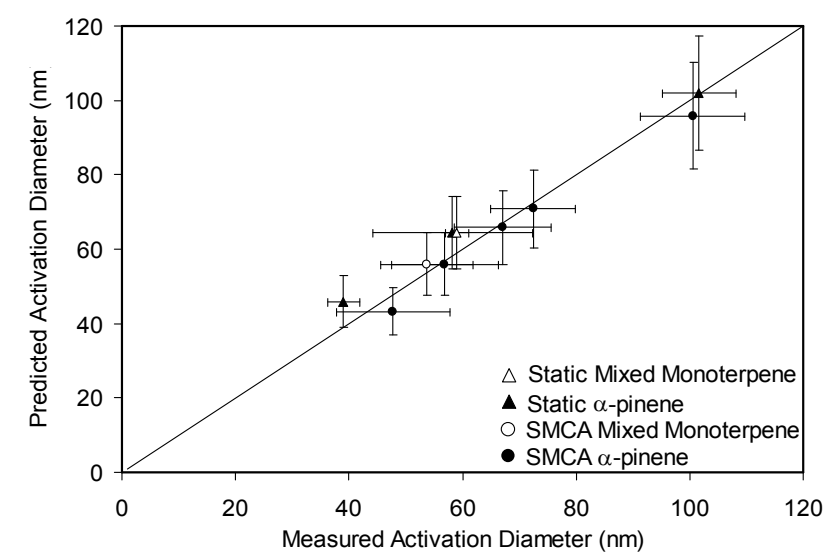

Fig. 14. Comparison of experimental activation diameter to calculated activation diameter for the static CCN counter (triangles) and for SMCA (circles). Solid markers are used for $\alpha$-pinene SOA and open markers for mixed monoterpene SOA. Measured activation diameter error bars reflect two standard deviations in the measurements and predicted activation diameter error bars reflect a $15 \%$ uncertainty in the Köhler theory prediction. The solid line is the $1: 1$ line.

but experiences a decrease in activation diameter of approximately $3 \mathrm{~nm} \mathrm{~h}^{-1}$ throughout the course of the experiment. A similar increase in $\mathrm{CCN}$ activity in the presence of hydroxyl radicals is observed in mixed monoterpene SOA measurements conducted by both instruments, with SMCA measuring an initial decrease in activation diameter of $1.6 \mathrm{~nm} \mathrm{~h}^{-1}$.

The two $\mathrm{CCN}$ instruments were in good agreement in terms of measured CCN activity of ammonium sulfate and of SOA generated during these experiments. Surface active organics are likely in SOA aerosol. We estimate that the organics in aged monoterpene aerosols depress surface tension by about $10 \mathrm{mN} \mathrm{m}^{-1}$. Using KTA, the molecular weight of the SOA was estimated to be $180 \mathrm{~g} \mathrm{~mol}^{-1}$ with a soluble fraction of approximately $65 \%$.

The monoterpene SOA is quite active as $\mathrm{CCN}$, average $\kappa=0.15 \pm 0.08$, and would likely be a good source of CCN in the atmosphere. The $\mathrm{CCN}$ behavior of aged $\alpha$-pinene and mixed monoterpenes is the same and is generally consistent the growing body of literature examining the CCN activity of lab-generated secondary organic aerosol. This strongly suggests that a simplified, common treatment of CCN activity for this type of SOA is possible in aerosol-cloud interaction studies. While KTA allows a much more detailed understanding of SOA CCN, roughly the same CCN activity can be predicted with a simplified (albeit less realistic) description of the aerosol, (complete solubility, surface tension of water) to within $15 \%$ of the diameters measured with the static $\mathrm{CCN}$ counter. Assuming that the SOA is completely soluble and neglecting the surface tension effects results in agreement with experiments to within $10 \%$ for the static CCN counter and within $5 \%$ for the DMT CFSTG CCN counter. 
Acknowledgements. This work was funded by the US National Science Foundation (ATM-0336296) and the EUCAARI European Union Project. G.J.E acknowledges the National Science Foundation Graduate Research Fellowship and the Achievement Rewards for College Scientists for support. A.A.A. acknowledges support from a NASA ESS fellowship and A.N. acknowledges support from an NSF CAREER award. We would like to thank G. Hagler and M. Bergin of the Georgia Institute of Technology for the use of their Sievers 900 Portable Total Organic Carbon (TOC) analyzer and Terry Lathem for his work on droplet growth analysis of mixed monoterpenes.

Edited by: A. Wiedensohler

\section{References}

Asa-Awuku, A., Nenes, A., Gao, S., Flagan, R. C., and Seinfeld, J. H.: Alkene ozonolysis SOA: inferences of composition and droplet growth kinetics from Köhler theory analysis, Atmos. Chem. Phys. Discuss., 7, 8983-9011, 2007a, http://www.atmos-chem-phys-discuss.net/7/8983/2007/.

Asa-Awuku, A., Sullivan, A. P., Hennigan, C. J., Weber, R. J., and Nenes, A.: Investigation of molar volume and surfactant characteristics of water-soluble organic compounds in biomass burning aerosol, Atmos. Chem. Phys., 8, 799-812, 2008, http://www.atmos-chem-phys.net/8/799/2008/.

Asa-Awuku, A., Engelhart, G., Lee, B. H., Pandis, S, and Nenes, A.: Relating CCN activity, volatility, and droplet growth kinetics of $\beta$-caryophyllene secondary organic aerosol, Atmos. Chem. Phys., 8, 10 105-10 151, 2008.

Bilde, M. and Svenningsson, B.: CCN activation of slightly soluble organics: the importance of small amounts of inorganic saltand particle phase, Tellus, 56B, 128-134, 2004.

Broekhuizen, K. E., Thornberry, T., Kumar, P. P., and Abbatt, J. P. D.: Formation of cloud condensation nuclei by oxidative processing: unsaturated fatty acids, J. Geophys. Res., 109, D24206, doi:10.1029/2004JD005298, 2004.

Chew, A. A. and Atkinson, R.: OH radical formation yields from the gas-phase reactions of $\mathrm{O}_{3}$ with alkenes and monoterpernes, J. Geophys. Res., 101, 28 649-28 654, 1996.

Chung, S. H. and Seinfeld, J. H.: Global distribution and climate forcing of carbonaceous aerosols, J. Geophys. Res., 107, D11102, doi:10.1029/2001JD001397, 2002.

Corrigan, C. E. and Novakov, T.: Cloud condensation nucleus activity of organic compounds: a laboratory study, Atmos. Environ., 33, 1661-1668, 1999.

Cruz, C. N. and Pandis, S. N.: A study of the ability of pure secondary organic aerosol to act as cloud condensation nuclei, Atmos. Environ., 31, 2205-2214, 1997.

Cruz, C. N. and Pandis, S. N.: The effect of organic coatings on the cloud condensation nuclei activation of inorganic atmospheric aerosol, J. Geophys. Res., 103, 13 111-13 123, 1998.

Dinar, E., Taraniuk, I., Graber, E. R., Katsman, S., Moise, T., Anttila, T., Mentel, T. F., and Rudich, Y.: Cloud condensation nuclei properties of model and atmospheric HULIS, Atmos. Chem. Phys., 6, 2465-2481, 2006,

http://www.atmos-chem-phys.net/6/2465/2006/.

Feingold, G. and Chuang, P. Y.: Analysis of the influence of filmforming compounds on droplet growth: Implications for cloud microphysical processes and climate, J. Atmos. Science., 59, 2006-2018, 2002.

Gill, P. S., Graedel, T. E., and Weschler, C. J.: Organic films on atmospheric aerosol-particles, fog droplets, cloud droplets, raindrops, and snowflakes, Rev. of Geophys., 21(4), 903-920, 1983.

Griffin, R. J., Cocker, D. R., and Seinfeld, J. H.: Estimate of global atmopheric organic aerosol from oxidation of biogenic hydrocarbons, Geophys. Res. Lett., 26, 2721-2724, 1999.

Guenther, A., Hewitt, C. N., Erickson, D., Fall, R., Geron, C., Graedel, T. E., Harley, P., Klinger, L., Lerdau, M., McKay, W. A., Pierce, T., Scholes, B., Steinbrecher, R., Tallamraju, R., Taylor, J., and Zimmerman, P.: A global model of natural volatile organic compound emissions, J. Geophys. Res., 100, 8873-8892, 1995.

Hegg, D. A., Gao, S., Hoppel, W., Frick, G., Caffrey, P., Leaitch, W. R., Shantz, N., Ambrusko, J., and Albrechcinski, T.: Laboratory studies of the efficiency of selected organic aerosols as CCN, Atmos. Res., 58, 155-166, 2001.

Hori, M., Ohta, S., Murao, N., and Yamagata, S.: Activation capability of water soluble organic substances as CCN, J. Aerosol Sci., 34, 419-448, 2001.

Houghton, J., Ding, Y., Griggs, D., Noguer, M., van der Linden, P., Dai, X., Maskell, K., and Johnson, C.: Climate Change, 2001: the Science of Climate Change, Cambridge University Press, New York, USA, and Cambridge, UK, 2001.

Huff Hartz, K. E., Rosenørn, T., Ferchak, S. R., Raymond, T. M., Bilde, M., Donahue, N. M., and Pandis, S. N.: Cloud condensation nuclei activation of monoterpene and sesquiterpene secondary organic aerosol, J. Geophys. Res., 110, D14208, doi:10.1029/2004JD005754, 2005.

IPCC (Intergovernmental Panel on Climate Change): Changes atmospheric constituents and in radiative forcing, in: Climate change 2007: the physical science basis, Cambridge University Press, New York, USA, and Cambridge, UK, 2007.

Jang, M. and Kamens, R. M.: Newly characterized products and composition of secondary aerosols from the reaction of a-pinene with ozone, Atmospheric Environment, 33, 459-474, 1999.

Keywood, M. D., Kroll, J. H., Varutbangkul, V., Bahreini, R., Flagan, R. C., and Seinfeld, J. H.: Secondary organic aerosol formation from cyclohexene ozonolysis: effect of $\mathrm{OH}$ scavenger and the role of radical chemistry, Environ. Sci. Technol., 38, 33433350, 2004.

King, S. M., Rosenoern, T., Shilling, J. E., Chen, Q., Martin, S. T.: Cloud condensation nucleus activity of secondary organic aerosol particles mixed with sulfate, Geophys. Res. Lett., 34, L24806, doi:10.1029/2007GL030390, 2007.

Kiss, G., Tombacz, E., and Hansson, H. C.: Surface tension effects of humic-like substances in the aqueous extract of tropospheric fine aerosol, J. Atmos. Chem., 50, 279-294, 2005.

Kiss, G., Varga, B., Galambos, I., and Ganszky, I.: Characterization of water-soluble organic matter isolated from atmospheric fine aerosol, J. Geophys. Res., 107, 8339, doi:10.1029/2001JD000603, 2002.

Köhler, H.: The nucleus in and the growth of hygroscopic droplets, Trans. Faraday Soc., 32, 1151-1161, 1936.

Kostenidou, E., Pathak, R. K., and Pandis, S. N.: An algorithm for the calculation of secondary organic aerosol density combining AMS and SMPS data, Aeros. Sci. Tech., 41, 1002-1010, 2007.

Kumar, P. P., Broekhuizen, and K., Abbatt, J. P. D.: Organic acids as 
cloud condensation nuclei: laboratory studies of highly soluble and insoluble species, Atmos. Chem. Phys., 3, 509-520, 2003, http://www.atmos-chem-phys.net/3/509/2003/.

Lance, S., Medina, J., Smith, J. N. and Nenes, A.: Mapping the operation of the DMT Continuous Flow CCN Counter, Aerosol Sci. Technol., 40, 1-13, 2006.

Lindinger, W., Hansel, A., and Jordan, A.: On-line monitoring of volatile organic compounds at pptv levels by means of protontransfer-reaction mass spectrometry (PTR-MS) medical applications, food control and environmental research, Int. J. Mass Spectrometry Ion Processes, 173, 191-241, 1998.

Nozière, B., Barnes, I., and Becker K.-H.: Product study and mechanisms of the reactions of $\alpha$-pinene and of pinonaldehyde with OH radicals, J. Geophys. Res., 104, 23 645-23 656, 1999.

Padró, L. T., Asa-Awuku, A., Morisson, R., and Nenes, A.: Inferring thermodynamic properties from $\mathrm{CCN}$ activation experiments: single-component and binary aerosols, Atmos. Chem. Phys., 7, 5263-5274, 2007, http://www.atmos-chem-phys.net/7/5263/2007/.

Padró, L. T. and Nenes, A.: Cloud droplet activation: solubility revisited, Atmos. Chem. Phys. Discuss., 7, 2325-2355, 2007, http://www.atmos-chem-phys-discuss.net/7/2325/2007/.

Petters, M. D. and Kreidenweis, S. M.: A single parameter representation of hygroscopic growth and CNN activity, Atmos. Chem. Phys., 7, 1961-1971, 2007,

http://www.atmos-chem-phys.net/7/1961/2007/.

Petters, M. D., Prenni, A. J., Kreidenweis, S. M., DeMott, P. J., Matsunaga, A., Lim, Y. B., and Ziemann, P. J.: Chemical aging and the hydrophobic-to-hydrophilic conversion of carbonaceous aerosol, Geophys. Res. Lett., 33, L24806, doi:10.1029/2006GL027249, 2006.

Petters, M. D., Prenni, A. J., Kreidenweis, S. M., and DeMott, P. J.: On measuring the critical diameter of cloud condensation nuclei using mobility selected aerosol, Aerosol Sci. Technol, 41, 907913, 2007.

Prenni, A. J., Petters, M. D., Kreidenweis, S. M., DeMott, P. J., and Ziemann, P. J.: Cloud droplet activation of secondary organic aerosol, J. Geophys. Res., 112, D10223, doi:10.1029/2006JD007963, 2007.

Presto, A. A., Huff Hartz, K. E. and Donahue, N. M.: Secondary organic aerosol production from terpene ozonolysis - 1: Effect of UV radiation, Environ. Sci. Technol., 39, 7036-7045, 2005a.

Presto, A. A., Huff Hartz, K. E. and Donahue, N. M.: Secondary organic aerosol production from terpene ozonolysis - 2: Effect of $\mathrm{NO}_{\mathrm{x}}$ concentration, Environ. Sci. Technol., 39, 7046-7054, $2005 b$.

Pruppacher, H. R. and Klett, J. D.: Microphysics of Clouds and Precipitation, Kluwer, Dordrecht, The Netherlands, 1997.

Raymond, T. M. and Pandis, S. N.: Cloud activation of single-component organic aerosol particles, J. Geophys. Res., 107(D24), 4787, doi:10.1029/2002JD002159, 2002.
Raymond, T. M. and Pandis, S. N.: Formation of cloud droplets by multicomponent organic particles, J. Geophys. Res., 108(D15), 4469, doi:10.1029/2003JD003503, 2003.

Roberts, G. C. and Nenes, A.: A continuous-flow streamwise thermal gradient $\mathrm{CCN}$ chamber for atmospheric measurements, Aerosol Sci. Technol., 39, 206-221, 2005.

Rose, D., Frank, G. P., Dusek, U., Gunthe, S. S., Andreae, and Pöschl, U.: Calibration and measurement uncertainties of a continuous-flow cloud condensation nuclei counter (DMTCCNC): CCN activation of ammonium sulfate and sodium chloride aerosol particles in theory and experiment, Atmos. Chem. Phys., 8, 1153-1179, 2008, http://www.atmos-chem-phys.net/8/1153/2008/.

Ruehl, C. R., Chuang, P. Y., and Nenes, A.: How quickly do cloud droplets form on atmospheric particles?, Atmos. Chem. Phys., 8, 1043-1055, 2008, http://www.atmos-chem-phys.net/8/1043/2008/.

Seinfeld, J. H. and Pankow, J. F.: Organic atmospheric particulate matter, Annu. Rev. Phys. Chem., 54, 121-140, 2003.

Shantz, N. C., Leaitch, W. R., and Caffrey, P. F.: Effect of organics on the growth rate of cloud droplets, J. Geophy. Res., 108, D54168, doi:10.1029/2002JD002540, 2003.

Shulman, M. L., Jacobson, M. C., Carlson, R. J., Synovec, R. E., and Young, T. E.: Dissolution behavior and surface tension effects of organic compounds in nucleating cloud droplets, Geophys. Res. Lett., 23, 277-288, 1996.

Stanier, C. O., Pathak, R. K., and Pandis, S. N.: Measurements of the volatility of aerosols from $\alpha$-pinene ozonolysis, Environ. Sci. Technol., 41, 2756-2763, 2007.

Sullivan, A. P. and Weber, R. J.: Chemical characterization of the ambient organic aerosol soluble in water - 1: Isolation of hydrophobic and hydrophilic fractions with a XAD-8 resin, J. Geophys. Res. Atmos., 111, D05314, doi:10.1029/2005JD006485, 2006.

Svenningsson, B., Rissler, J., Swietlicki, E., Mircea, M., Bilde, M., Facchini, M. C., Decesari, S., Fuzzi, S., Zhou, J., Monster, J., Rosenorn, T.: Hygroscopic growth and critical supersaturations for mixed aerosol particles of inorganic and organic compounds of atmospheric relevance, Atmos. Chem. Phys., 6,1937-1952, 2006.

Twomey, S.: Measurements of natural cloud nuclei, J. Rec. Atmos, 1, 101-105, 1963.

VanReken, T. M., Ng, N. L., Flagan, R. C., and Seinfeld, J. H.: Cloud condensation nucleus activation properties of biogenic secondary organic aerosol, J. Geophy. Res., 110, D07206, doi:10.1029/2004JD005465, 2005.

Zhang, J., Huff Hartz, K. E., Pandis, S. N., and Donahue, N. M.: Secondary organic aerosol formation from limonene ozonolysis: homogeneous and heterogeneous influences as a function of $\mathrm{NO}_{\mathrm{x}}$, J. Phys. Chem A, 110, 11 053-11 063, 2006. 